\title{
Penile Leiomyoma
}

National Cancer Institute

\section{Source}

National Cancer Institute. Penile Leiomyoma. NCI Thesaurus. Code C162583.

A leiomyoma that occurs in the penis. 